\title{
Forgiveness and the Need to Belong
}

Personality and Social

Psychology Bulletin

36(9) II48-1160

(C) 2010 by the Society for Personality and Social Psychology, Inc

Reprints and permission: http://www. sagepub.com/journalsPermissions.nav DOI: $10.1177 / 0|46| 67210378852$

http://pspb.sagepub.com

\author{
Collin D. Barnes', Mauricio Carvallo', \\ Ryan P. Brown', and Lindsey Osterman'
}

(S)AGE

\begin{abstract}
People who experience a strong need to belong might be particularly inclined to forgive wrongdoings to preserve social bonds. Three studies that utilized different methods and measures of forgiveness consistently demonstrated this is not the case. The authors found that individuals high in the need to belong report practicing forgiveness with less frequency and value it no more than those low in the need to belong (Study I). In Study 2, they found that satisfying the need to belong led participants to express greater willingness to forgive hypothetical offenses compared to participants in a control group. Finally, in Study 3, the authors linked the need to belong to forgiveness of specific transgressions and found that this negative relationship was mediated by offense-related anger and perceptions of offense severity. These findings suggest that needing to belong paradoxically interferes with forgiveness, even though forgiving could promote the satisfaction of belongingness needs following transgressions.
\end{abstract}

\section{Keywords}

belonging, attachment, forgiveness, social rejection, social acceptance, transgressions

Received July 31, 2009; revision accepted March 12, 2010

Although we might wish sometimes to exchange our fractured and damaged relationships for better functioning ones, the reality is that dropping one relationship to pick up another of the same depth and quality is not a quick or easy process. The going often gets tough in human relationships. If people responded to all interpersonal conflicts by ending their relationships to start over with new ones, they would be in a perpetual state of seeking belongingness but never experiencing it, and this would run counter to the fundamental need to belong that animates much human behavior (Baumeister \& Leary, 1995). What, then, are people to do in the face of relational difficulties? One solution is to offer forgiveness to wrongdoers. Although forgiveness is not tantamount to reconciliation (McCullough, Pargament, \& Thoresen, 2000), it is one link in the chain of relationship restoration, and in a world where close, fulfilling social bonds are not always easy or possible to come by, people might find it worthwhile to forgive wrongdoers to meet their need for interpersonal connectedness.

The idea that a positive association between the need to belong and forgiveness should exist seems intuitive. Nevertheless, empirical support for such a link is lacking in the psychological literature, and the extant research on related topics suggests that the need to belong might make preserving relationships that have been abused by transgressions especially difficult and unlikely. The purpose of this article, therefore, is to take an initial foray into the study of how the need to belong relates to interpersonal forgiveness by addressing a few basic questions on the topic using different methods and measures. In the following sections we discuss the theory of the need to belong and then explore evidence that points to how this motive might relate to forgiveness to set the stage for our own investigations.

\section{Need to Belong: Theory and Research}

There are many things in life that we can do without: designer jeans, fried foods, celebrity tabloids, and luxury cars, to name a few. According to Baumeister and Leary (1995), however, no one would make it very well in life without a few stable, caring relationships. In their seminal article on the topic, these authors argued that humans have an innate need to belong - that is, a need to secure and maintain a minimum number of personal relationships that are characterized by frequent, positive (or, at least nonnegative) interactions, mutual emotional concern, and constancy. Through an extensive literature review, Baumeister and Leary (1995) established that people's need to be connected with others is

'University of Oklahoma, Norman, OK, USA

Corresponding Author:

Ryan P. Brown, University of Oklahoma, Department of Psychology, 455

W. Lindsey, DHT 705, Norman, OK 73019

Email: rpbrown@ou.edu 
fundamental (i.e., not derivative of other motives) and is essential to health and well-being. Thus, as is true with the need for food and safety (Maslow, 1968), the need to belong is associated with important emotional consequences, directs cognitive processing, guides behavior, is active under all but the most adverse conditions, applies to people from every culture, and is associated with negative physical and psychological outcomes when it goes unmet.

The proposition that humans have a fundamental need to form close interpersonal attachments not only provides a unifying theme for a great deal of the social psychological literature to date but also has sparked new lines of research and has suggested novel ways of conceptualizing established constructs (e.g., Leary, Tambor, Terdal, \& Downs, 1995). Scholars have invoked the need to belong in research on the personal-group discrimination discrepancy (Carvallo \& Pelham, 2006), dismissing avoidant attachment style (Carvallo \& Gabriel, 2006), sensitivity to social cues (Pickett, Gardner, \& Knowles, 2004), self-regulatory performance (DeWall, Baumeister, \& Vohs, 2008), suicide (Joiner, Hollar, \& Van Orden, 2006), cooperation in public goods dilemmas (De Cremer \& Leonardelli, 2003), life and relationship satisfaction (Mellor, Stokes, Firth, Hayashi, \& Cummins, 2008), and homesickness (Watt \& Badger, 2009). In the present article, we seek to expand on the existing literature by linking the need to belong with interpersonal forgiveness. Below, we explain why and how these constructs might be related.

\section{Forgiveness and the Need to Belong}

We began this article with the argument that forgiveness might be a means to restoring intimacy in a world in which building new social connections is not always easy or possible (Baumeister \& Leary, 1995; see also Richman \& Leary, 2009). In light of this reasoning, it seems plausible to expect a positive association between the need to belong and forgiveness, such that people who have a strong craving for belongingness demonstrate a greater likelihood of extending forgiveness to wrongdoers than those whose need to belong is less pronounced. We refer to this possibility as Hypothesis 1 .

This argument is not so different from hypotheses offered by scholars who have examined the effects of social exclusion on aggression. These scholars have built on the need to belong to argue that social exclusion should lead to compensatory behaviors aimed at achieving social acceptance (DeWall, Twenge, Gitter, \& Baumeister, 2009; Leary, Twenge, \& Quinlivan, 2006; Twenge, Baumeister, Tice, \& Stucke, 2001; Twenge et al., 2007; Williams, 1997), and under some conditions they do just that (Williams, Cheung, \& Choi, 2000; Williams \& Sommer, 1997). Surprisingly, however, the vast majority of studies suggest that people react to rejection with anger (Buckley, Winkel, \& Leary, 2004; Bushman, Baumeister, \& Phillips, 2001; Williams et al.,
2000) and aggression (Kirkpatrick, Waugh, Valencia, \& Webster, 2002; Twenge et al., 2001). The finding that social exclusion increases aggression, even toward neutral third parties (Twenge et al., 2001; Warburton, Williams, \& Cairns, 2006), is remarkably robust.

Although aggression and forgiveness are separable constructs, when retaliatory aggression is present, forgiveness is surely absent (Brown, 2004; McCullough, Worthington, \& Rachal, 1997). Therefore, it stands to reason that complementary outcomes might obtain with forgiveness as has been shown to occur with aggression, but this would suggest that the exact opposite of Hypothesis 1 is true: People who chronically or momentarily have a strong need to belong might be more likely to withhold than to extend forgiveness to transgressors. We refer to this potential outcome as Hypothesis 2. Additional evidence for this somewhat counterintuitive hypothesis comes from research on adult attachment styles and forgiveness, which we discuss next.

\section{Individual Differences in the Need to Belong, Attachment, and Forgiveness}

Baumeister and Leary (1995) argue that although "[t]he need to belong should ... be found to some degree in all humans in all cultures, ... one would expect there to be individual differences in [its] strength and intensity" (p. 499). That is, some individuals should have a larger social appetite than others, irrespective of the status of their current social connections. Based on this assumption, Schreindorfer and Leary (1996) developed a self-report instrument for tapping individuals' desire to be accepted by and connected with others, which was modified by Kelly (1999) and then used in a series of studies by Leary, Kelly, Cottrell, and Schreindorfer (2008) to show that individual differences in the need to belong are distinguishable from individual differences in related constructs (e.g., desire for affiliation, loneliness, social anxiety, rejection sensitivity). Close inspection of the statements included in the scale reveals that it captures both the strength of individuals' desires for belongingness (e.g., "I want other people to accept me," "I have a strong 'need to belong"') and the extent to which they worry about and are bothered by experiences that connote a lack of acceptance (e.g., "My feelings are easily hurt when I feel that others do not accept me," "It bothers me a great deal when I am not included in other people's plans"). Thus, high scores on the Need to Belong Scale (NTBS) appear to characterize individuals who have a powerful urge to be accepted by others but who experience insecurity over their belongingness, as though their personal connections are constantly hanging in the balance and could easily terminate.

Individual differences in the need to belong, thus, bear some resemblance to insecure attachment (perhaps especially the preoccupied attachment style), which in turn has been shown to be negatively associated with both state and 
trait forgiveness (Brown \& Phillips, 2005; Burnette, Taylor, Worthington, \& Forsyth, 2007; Kachadourian, Fincham, \& Davila, 2004; Lawler-Row, Younger, Piferi, \& Jones, 2006; Webb, Call, Chickering, Colburn, \& Heisler, 2006). Furthermore, Leary et al. (2008) report that the NTBS correlates with measures of neuroticism, fear of rejection, and manifestations of borderline personality disorder in normal persons, all of which have conceptual links with insecure attachment and one of which (neuroticism) has been shown to be negatively associated with measures of forgiveness (Brown, 2003; McCullough, Bellah, Kilpatrick, \& Johnson, 2001). Such empirical links suggest (in support of Hypothesis 2) that higher scores on the NTBS should characterize people who exhibit difficulty in forgiving, despite the potential impetus to forgive created by this very need.

\section{Overview of the Present Studies}

The primary question in the present investigations is whether forgiveness is positively (Hypothesis 1) or negatively (Hypothesis 2) associated with the need to belong. In Study 1 we examined this relationship correlationally and distinguished between two components of dispositional forgiveness (forgiveness tendencies and forgiveness values) that might differentially relate to individuals' belongingness needs. In Study 2 we experimentally primed the satisfaction of the need to belong and examined how promoting a sense of belongingness affected forecasted forgiveness for imagined offenses. Finally, in Study 3 we explored the cognitive and affective underpinnings of the relationship between the need to belong and forgiveness for specific, real-life offenses to examine more precisely why the need to belong might be related to forgiveness.

\section{Study I}

Study 1 was designed to examine the link between needing to belong (as assessed by the NTBS), forgiveness tendencies, and forgiveness attitudes. If Hypothesis 1 is correct, this need should be associated with greater forgiveness tendencies, but if Hypothesis 2 is correct, the reverse association should emerge. Because people who have a strong need to belong presumably value relationship-promoting behaviors, such as forgiveness, irrespective of their tendencies to perform such behaviors, Hypothesis 1 might also lead us to expect a positive association between the NTBS and proforgiveness attitudes (cf. Brown, Barnes, Judice-Campbell, 2007; Tsang, McCullough, \& Hoyt, 2005).

\section{Method}

Participants. Participants were 163 undergraduates (133 females) at the University of Oklahoma who received course credit for taking part in the study. One participant (female) was eliminated from the data set for scoring over 4 $S D$ s below the mean on the ATF (described below).

Materials and procedure. In small groups of 1 to 4, participants completed the following scales as part of a larger study of forgiveness. Scales were completed by participants in the order presented below.

Self-esteem. Participants' self-esteem was measured with the 10-item Rosenberg Self-Esteem Scale (RSE; Rosenberg, 1965) and was treated as a covariate in our analyses to demonstrate that any association between the need to belong and forgiveness could not be attributed to participants' selfesteem, which has been previously associated with social inclusion (e.g., Leary et al., 1995). The RSE exhibited good reliability in this sample $(\alpha=.77)$. Level of agreement with each statement included on the RSE (e.g., "I feel that I'm a person of worth, at least on an equal basis with others" and "On the whole, I am satisfied with myself") was measured using a scale ranging from 1 (strongly disagree) to 7 (strongly agree).

Forgiveness. Participants completed Brown's (2003) sixitem Attitudes Toward Forgiveness Scale (ATF), which measures the extent to which respondents value forgiveness (e.g., "I believe forgiveness is a moral virtue" and "It is admirable to be a forgiving person"), and the four-item Tendency to Forgive Scale (TTF), which taps respondents' past forgiveness experiences (e.g., "I tend to get over it quickly when someone hurts my feelings" and "When people wrong me, my approach is just to forgive and forget"). In support of the validity of these scales, Brown has shown that people's self-reported forgiveness tendencies (TTF scores) are corroborated by their romantic partners and that the TTF is a better predictor of mental health (e.g., depression and life satisfaction) than the ATF. Also, Brown et al. (2007) have demonstrated that religious fundamentalists esteem forgiveness but do not practice it with much frequency, which suggests that valuing forgiveness is not tantamount to being a forgiving person (also see Tsang et al., 2005). Both the ATF and TTF demonstrated acceptable internal reliability in this sample ( $\alpha=.65$ and $\alpha=.74$, respectively). Participants rated their level of agreement with each of the statements included on the ATF and TTF on a scale ranging from 1 (strongly disagree) to 7 (strongly agree).

Need to belong. Individual differences in participants' need to belong were assessed with the 10-item NTBS (Leary et al., 2008), described earlier. Participants rated the extent to which each statement in the NTBS was characteristic of them on a scale ranging from 1 (not at all) to 7 (extremely). The internal reliability of the NTBS was good $(\alpha=.83)$.

Attachment. Using Bartholomew and Horowitz's (1991) instrument, participants rated on a scale ranging from 1 (strongly disagree) to 7 (strongly agree) how much they agreed with each of four statements describing the secure, dismissing, preoccupied, and fearful attachment styles. Models of self (attachment anxiety) and models of others 
(attachment avoidance) in close relationships were computed using Griffin and Bartholomew's (1994) method.

\section{Results and Discussion}

Descriptive statistics for and intercorrelations among the variables examined in Study 1 appear in Table 1. To test our competing hypotheses regarding the relationships among the NTBS, forgiveness tendencies (TTF), and forgiveness values (ATF), we constructed two regression equations: one with TTF scores as the criterion variable and the other with ATF scores as the criterion variable. In both equations, participants' NTBS scores were treated as the predictor variable of interest and participants' gender, self-esteem scores, and attachment system anxiety and avoidance scores were treated as covariates.

Contrary to Hypothesis 1, we found that the NTBS was negatively related to the TTF, $\beta=-.28, t=-3.46, p=.001$. Participants' level of attachment anxiety was the only other significant predictor of the TTF, $\beta=-.17, t=-2.00, p=.048$. Based on this analysis, it appears that those who have a strong need to belong are more inclined to hold grudges than to forgive those who have wronged them. Importantly, we found this to be true even with a well-established measure of attachment dimensions controlled.

This finding does not preclude the possibility that individual differences in belongingness needs are positively related to valuing forgiveness. Indeed, if people who deeply desire belongingness esteem behaviors that promote the vitality of relationships, we would expect a positive association to exist between these variables. We tested this possibility in a second regression analysis of ATF scores. Contrary to Hypothesis 1 , the NTBS and ATF were nonsignificantly related to each other, $\beta=.05$, ns. In addition, none of the covariates in the model was significant.

The results of Study 1 support Hypothesis 2 rather than Hypothesis 1, showing that those who have an especially strong need to belong tend to be less rather than more inclined to extend forgiveness to those who have wronged them. On the recommendation of an anonymous reviewer, we examined in a separate data set of 83 respondents whether the association between scores on the NTBS and the TTF might be attributable to their covariance with a conceptually similar third variable - namely, rejection sensitivity (Downey \& Feldman, 1996). Importantly, we found that the NTBS significantly predicted scores on the TTF, $\beta=-.30, t=-2.74$, $p=.008$, even when scores on the Rejection Sensitivity Questionnaire (RSQ) were controlled. The RSQ, on the other hand, failed to predict any unique variance in the TTF, $\beta=.05, n s$. This supplementary finding lends further support to the unique, negative association between needing to belong and forgiveness tendencies reported above.

Although supportive of Hypothesis 2, these results are correlational in nature and prevent us from drawing conclusions about the causal relationship between needing to belong
Table I. Intercorrelations Among and Descriptive Statistics for Study I Variables

\begin{tabular}{lcccccc}
\hline & NTBS & TTF & ATF & RSE & Anxiety & Avoidance \\
\hline NTBS & .83 & & & & & \\
TTF & $-.33^{* *}$ & .74 & & & & \\
ATF & .05 & $.20^{*}$ & .65 & & & \\
RSE & $-.16^{*}$ & $.18^{*}$ & .00 & .77 & & \\
Anxiety & $.28^{* *}$ & $-.26^{* *}$ & -.13 & $-.36^{* *}$ & - & \\
Avoidance & $-.24 * *$ & .01 & -.15 & $-.17^{*}$ & .09 & - \\
M & 5.14 & 4.15 & 5.56 & 6.56 & -1.43 & -0.69 \\
SD & 1.01 & 1.29 & 0.79 & 0.76 & 4.28 & 4.39 \\
\hline
\end{tabular}

Note: $N=162$. NTBS $=$ Need to Belong Scale; TTF $=$ Tendency to Forgive Scale; ATF = Attitudes Toward Forgiveness Scale; RSE $=$ Rosenberg Self-Esteem Scale; anxiety = attachment anxiety; avoidance = attachment avoidance. Scale alphas appear on the diagonal.

$* p \leq .05 . * * p \leq .001$.

and forgiveness. Thus, in Study 2 we addressed this issue experimentally by manipulating the satisfaction of belongingness needs.

\section{Study 2}

Altering fundamental desires for social acceptance through a laboratory manipulation is almost certainly impossible given the deep-seated nature of such desires (Bowlby, 1969). However, several studies have demonstrated that it is possible to induce belongingness satisfaction simply by having individuals contemplate important social bonds in their lives (e.g., Mickulincer, Shaver, Gillath, \& Nitzberg, 2005; Twenge et al., 2007). Therefore, in Study 2, we employed a manipulation similar to that used by Twenge et al. (2007) with the goal of temporarily satisfying belongingness needs in one group of participants and comparing their predicted forgiveness of several hypothetical offenses to those of participants whose belongingness needs were left unaltered. Unlike Twenge et al. (2007), however, we sought to satiate belongingness desires over baseline levels, not to replenish feelings of belongingness after a rejection experience.

We once again pitted Hypothesis 1 against Hypothesis 2 in this experiment, reasoning from the results of Study 1 that individuals whose belongingness needs are satisfied would feel relatively more secure in others' acceptance of them than would individuals whose desires for belongingness were left unaltered (see Carvallo \& Pelham, 2006). Manipulating belongingness satisfaction in this way, we hoped to create momentarily high and low need to belong groups experimentally analogous to the high and low scorers on the NTBS in Study 1.

\section{Method}

Participants. Participants were 134 undergraduates at the University of Oklahoma. Because of either high levels of 
suspicion or missing values on one or more key variables, 8 participants were dropped from the analyses reported below, leaving a total sample of 126 (98 females).

Materials and procedure. Participants were told that the study was designed to help researchers "learn more about college students' personalities and relationships." Participants were placed in individual cubicles containing computers and were randomly assigned to think and write about either an important close relationship (satisfied belongingness condition) or their daily diet over the past week (unaltered belongingness condition). In the satisfied belongingness condition, participants were instructed to think about a favorite family member or close friend and to consider why they liked him or her and why they felt the relationship was important. Participants then wrote about the relationship, focusing on conveying how they felt and what they thought about the person they selected. To complete these tasks, 8 minutes were allotted for participants. In the unaltered belongingness condition, participants spent 8 minutes writing an essay about their diet over the past week. They were told to describe what they had eaten and why and how they felt about their diet during that time period. After completing these tasks, participants responded to several forgiveness measures. Mood and self-esteem were also assessed.

Forgiveness. Forgiveness was measured with the Transgression Narrative Test of Forgivingness (TNTF; Berry, Worthington, Parrott, O'Connor, \& Wade, 2001). The TNTF requires respondents to imagine themselves as the victims of five interpersonal offenses and to forecast their likelihood of forgiving each one. Participants made their predictions using a scale on which 1 represented an unforgiving response to an imagined offense (definitely not forgive) and 5 indicated a forgiving response (definitely forgive). The TNTF demonstrated modest but acceptable internal reliability in this sample $(\alpha=.68)$. This measure has been used in previous investigations on the effects of priming a forgiving mind-set (Karremans \& Van Lange, 2005). For exploratory purposes, we also had participants report their forgiveness tendencies and forgiveness values using the TTF and ATF described in Study 1. Four additional statements were included on the ATF in an attempt to enhance its internal reliability (e.g., "Forgiveness is for people who are too scared to stick up for themselves" and "The world would be a better place if more people were forgiving"). Ratings on the TTF and ATF were made using the same 7-point scales described in Study 1. Both instruments demonstrated acceptable internal reliability in this sample $(\alpha$ $=.76$ for the TTF and ATF). These three forgiveness measures were administered in a counterbalanced order.

Self-esteem. After the forgiveness measures were administered, participants' self-esteem was assessed using the RSE, described in Study 1. Participants rated their level of agreement with each statement on the RSE using a scale ranging from 1 (strongly disagree) to 9 (strongly agree). The RSE demonstrated good reliability in this sample $(\alpha=.78)$.
Mood. Finally, we assessed mood using Watson, Clark, and Tellegen's (1988) Positive and Negative Affect Schedule (PANAS). Participants indicated the extent to which they were experiencing each emotion included on the PANAS "at this moment" using a scale ranging from 1 (slightly or not at all) to 5 (extremely). The positive $(\alpha=.87)$ and negative ( $\alpha=.86$ ) dimensions of the PANAS showed strong internal reliability among our participants.

After completing these measures, participants were given the opportunity to explain what they believed the study was about for their level of suspicion to be determined. Participants were then debriefed, thanked for their contribution to the study, and excused from the laboratory.

\section{Results and Discussion}

We submitted participants' forgiveness forecasts on the TNTF to a 2 (writing condition) $\times 6$ (forgiveness questionnaire order) ANOVA. In support of Hypothesis 2, participants in the satisfied belongingness condition who focused on an important close relationship $(M=3.23, S E=0.09)$ indicated that they would be, on average, more forgiving of the offenses on the TNTF than participants in the unaltered belongingness condition who considered their daily diet over the past week $(M=2.96, S E=0.08), F(1,114)=5.15, p=.025$. Neither the questionnaire order, $F(5,114)=1.01$, ns, nor the interaction between questionnaire order and writing condition, $F(5,114)=1.23$, $n s$, had an effect on forgiveness predictions. Thus, it appears that simply reminding people of a key relationship with a close other and having them focus on their thoughts and feelings about this person may be sufficient for satisfying belongingness needs and enhancing individuals' willingness to forgive relative to those whose need to belong is left unmet.

We followed up this primary analysis with two tests in which the impact of the writing task manipulation on participants' TTF and ATF scores, the criterion variables of interest in Study 1, was explored. These analyses revealed that participants in the satisfied belongingness condition $(M=4.32$, $S E=0.15)$ reported significantly higher scores on the TTF relative to participants in the unaltered belongingness condition $(M=3.72, S E=0.14), F(1,114)=8.13, p=.005$; no questionnaire order, $F(5,114)=0.26$, $n s$, or interaction effect, $F(5,114)=1.09, n s$, was detected. Participants in both groups reported statistically indistinguishable scores on the ATF, $F(1,114)=0.24, n s$; for this variable as well, no effect of questionnaire order, $F(5,114)=0.31, n s$, and no interaction, $F(5,114)=1.52, n s$, was found. The results for the TTF and ATF map nicely onto the findings of Study 1; however, it is intriguing that the manipulation caused participants in the satisfied belongingness condition to report significantly higher chronic forgiveness tendencies than participants in the unaltered belongingness condition. This suggests that the manipulation may have activated a forgiving 
mind-set in participants that caused them to see themselves as generally forgiving people.

It is conceivable that the manipulation produced changes in participants' self-esteem or mood, which, in turn, might account for the effects we found. It would not be surprising if self-esteem were affected by the manipulation, given the sensitivity of self-esteem to cues of social acceptance (Leary et al., 1995), but finding an effect of the manipulation on mood would be concerning if it accounted for the condition differences discussed above, as it would suggest that the manipulation might not have altered belongingness needs at all but primarily served as a mood induction. To test these possibilities and determine whether the manipulation had a direct effect on forgiveness, we submitted participants' RSE and mood (assessed by the positive and negative subscales of the PANAS) to separate two-way ANOVAs that crossed the belongingness satisfaction manipulation with questionnaire order. No effect of the manipulation obtained for the RSE, $F(1,114)=0.01, n s$, or either the positive, $F(1,114)=2.01$, $n s$, or negative, $F(1,114)=0.14, n s$, dimensions of the PANAS. No effect of questionnaire order was observed for any of these variables. Including participants' scores on these scales along with gender as covariates in the analyses reported above did not alter the results for any of the forgiveness measures. Thus, in line with Hypothesis 2, participants who had their belongingness needs momentarily satisfied reported greater willingness to forgive others for their wrongdoings than participants whose belongingness needs were left unaltered. These effects were independent of gender, self-esteem, and mood.

The question that arises in light of the consistent results of our first two studies is this: Why is forgiveness less likely among those who have a strong need to belong? In Study 3 we examined the mediating role of multiple cognitive and affective variables in the relationship between the need to belong and forgiveness to identify some of the psychological mechanisms that might be at work. To complement the dispositional and hypothetical forgiveness measures used in the first two studies, we included an index of state forgiveness for an actual, specific offense as the focal measure of Study 3 .

\section{Study 3}

The affective mechanisms we focused on in this investigation included some of those that scholars agree characterize reactions to negative relationship events - namely, anger, fear, and sadness (Gottman, 1993; Leary, Springer, Negel, Ansell, \& Evans, 1998; McCullough et al., 1997; McCullough et al., 1998). There is little doubt that these emotions are experienced to some degree by all people who suffer transgressions, but we suspect that they might be especially pronounced among those who have strong desires to belong. Insofar as affective reactions to a frustrated goal increase with the strength of the motivation to achieve that goal, then people who are highly committed to securing acceptance from others should experience more intense negative emotions (e.g., anger, fear, and sadness) when this goal is thwarted by an offense (cf. Diener, Larsen, \& Emmons, 1984; Emmons \& Diener, 1986). Because anger, fear, and sadness are thought to be some of the affective substrates of forgiveness (McCullough et al., 1997; McCullough et al., 1998), we examined all three as potential mediators of the association between the need to belong and forgiveness, although the work of Burnette et al. (2007) suggests that the role of anger in this relationship might be especially important.

People high in the need to belong might also think about offenses in ways that make forgiveness less likely. The first cognitive variable we believed might mediate the link between needing to belong and state forgiveness was victims' expectation that the offense would be repeated. Those who long for social acceptance might abide by the principal of "once bitten, twice shy." Insofar as forgiveness opens victims up to further harm by their offenders (Exline \& Baumeister, 2000), people who have a strong need to belong might be less forgiving because they are hypervigilant to protecting themselves against social exclusion (Molden, Lucas, Gardner, Dean, \& Knowles, 2009). Expecting repeat offenses from a transgressor could be a means of justifying the withholding of forgiveness and backing away from relationships that frustrate belongingness desires. The second cognitive variable we examined was the extent to which victims believed offenders meant to do them harm. It is possible that people with a strong need to belong attribute hostile intent to their offenders to justify unforgiving sentiments (e.g., anger) and motives (e.g., avoidance) that they think will protect them from further suffering (Baumeister, Stillwell, \& Wotman, 1990). The third and final cognitive variable we considered was victims' ratings of the subjective severity of the offense. People high in the need to belong might typically perceive transgressions as more hurtful, serious, and offensive than do those who are relatively low in this need, and these perceptions should make forgiveness less likely.

\section{Method}

Participants. For credit in their introductory psychology courses, 107 undergraduates at the University of Oklahoma participated in the study. Because of computer malfunctions, the responses of 10 participants were not recorded, which reduced our total sample to 97 (65 females). An additional 6 participants were missing total scale scores on either the sadness (2), anger (1), fear (1), or state forgiveness (2) variables described below. To recover these data, we imputed the appropriate scale mean for each missing value (McKnight, McKnight, Sidani, \& Figueredo, 2007). 
Materials and procedure. As a part of a larger investigation on interpersonal forgiveness, participants selected and wrote about an offense experience (one that occurred within the past 3 months) in which someone "wronged, mistreated, offended, or betrayed" them. Respondents were told that the offender could be a friend, acquaintance, stranger, family member, romantic partner, employer, coworker, and so on and that the wrongdoing or offense could be an action (something someone said or did) or an inaction (something someone failed to say or do that they should have). After recalling and writing about the offense, participants responded to the following items and instruments on a computer-based questionnaire.

Need to belong. Individual differences in the need to belong were assessed using the NTBS, described earlier. Participants rated the extent to which each item was characteristic or descriptive of them on a scale ranging from 1 (not at all) to 7 (extremely). The internal reliability of the NTBS was good $(\alpha=.81)$.

Forgiveness. Offense-specific forgiveness was measured using the Brown and Phillips (2005) State Forgiveness Scale (SFS). The SFS includes seven items designed to capture the extent to which respondents' are currently experiencing several forgiveness-related thoughts ("I hope this person gets what's coming to them for what they did to me"), feelings ("I feel warmly toward this person"), and behavioral inclinations ("If I saw this person again, I would try to avoid interacting with him/her"). The full SFS includes one item that explicitly asks about respondents' anger toward offenders ("I am angry at this person"), which we omitted from the scale to more conservatively test the mediating role of anger in the association between the NTBS and state forgiveness. The internal reliability of the abbreviated SFS was excellent $(\alpha=.90)$ and negligibly different from that of the full scale $(\alpha=.91)$.

Repeat offense likelihood, intentionality, and offense severity. Repeat offense likelihood was evaluated by having participants respond to the question "How likely is this person to do something like this to you again?" on a scale ranging from 1 (not at all) to 7 (extremely). Intentionality was assessed by having participants indicate the extent to which they believed the offender's behaviors were (a) intentional and (b) premeditated on a 7-point scale ranging from 1 (not at all) to 7 (completely). The internal reliability of the intentionality scale was good $(\alpha=.83)$. Participants also rated how hurtful, serious, and offensive the transgression was and how rejected they felt as a result of the offense at the time it occurred on a scale ranging from 1 (not at all) to 7 (extremely); these ratings were averaged together to create a composite severity scale $(\alpha=.71)$.

Anger, sadness, and fear. Participants indicated how "angry," "indignant," and "hostile" (anger, $\alpha=.81$ ), how "afraid," "anxious," and "uncomfortable" (fear, $\alpha=.67$ ), and how "sad," "depressed," and "hurt" (sadness, $\alpha=.86$ ) they currently felt concerning the offense on a scale ranging from 1 (not at all) to 7 (very much). Ratings for each adjective were averaged together to create a composite scale for each emotion.

In addition, we assessed preoffense intimacy levels between participants and offenders (a composite of participants' ratings of how close, committed, connected, and deep their relationships with their offenders were prior to the transgression; $\alpha=.98$ ) and whether offenders had apologized for their actions.

\section{Results and Discussion}

As our strategy for data analysis, we relied on a new multiple mediator technique devised by Preacher and Hayes (2008). This technique is especially useful in small samples, where the $p$ values associated with traditional Sobel tests may be suspect, and when multiple mediators are posited. Preacher and Hayes's approach allows for more accurate significance tests of mediation paths through bootstrapping, which entails resampling many times from an observed data set and computing the product of the path weights leading to and from a proposed mediator on each resample. These products are arranged in a distribution to create an empirically based sampling distribution from which bootstrapped confidence intervals can be obtained. A mediation path is said to be significantly different from zero if its confidence interval does not include zero. Also, with Preacher and Hayes's approach, it is possible to perform contrasts that compare the relative strength of the mediators contained in the model to determine which of the mediators, if any, are the primary channels by which a predictor variable is related to a criterion variable.

To avoid expending degrees of freedom unnecessarily and weakening the statistical power of our analyses, we examined the intercorrelations between participants' scores on the SFS and several potential confounding variables. We determined from these correlations that offender apology $(r=.42, p<.001)$ and preoffense intimacy ( $r=.48, p=.001)$ would be useful covariates in the model we tested. Participants' gender was totally unrelated to state forgiveness $(r=.002, n s)$, so it was not included as a covariate in our analyses.

In the multiple mediator model we examined, participants' NTBS scores were treated as the predictor variable, their scores on the abbreviated SFS as the criterion variable, and their ratings on the affective (anger, fear, and sadness) and cognitive (intentionality, repeat offense likelihood, and offense severity) variables as the potential mediators. The mediational utility of the affective and cognitive variables in this model was examined simultaneously. Intercorrelations among these measures appear in Table 2.

The multiple mediator model relies on ordinary least squares regression to calculate the weights of each of the paths contained in the model. The path weights (unstandardized betas) and a diagram of the model we tested appear in 
Table 2. Intercorrelations Among and Descriptive Statistics for Study 3 Variables

\begin{tabular}{|c|c|c|c|c|c|c|c|c|c|c|}
\hline & I & 2 & 3 & 4 & 5 & 6 & 7 & 8 & 9 & 10 \\
\hline I. NTBS & .81 & & & & & & & & & \\
\hline 2. SFS & $-.29 * *$ & .90 & & & & & & & & \\
\hline 3. Anger & $.30 * *$ & $-.40 * *$ & .81 & & & & & & & \\
\hline 4. Fear & .17 & -.09 & $.50 * *$ & .67 & & & & & & \\
\hline 5. Sadness & $.22 *$ & -.17 & $.70 * *$ & $.55^{* *}$ & .86 & & & & & \\
\hline 6. Intentionality & .15 & $-.46 * *$ & .18 & -.11 & .01 & .83 & & & & \\
\hline 7. ROL & $.28 * *$ & -.19 & $.24 *$ & .00 & $.35^{* *}$ & .18 & - & & & \\
\hline $\begin{array}{l}\text { 8. Offense } \\
\text { severity }\end{array}$ & $.32 * *$ & $-.62^{* *}$ & $.38^{* *}$ & .08 & $.36 * *$ & $.56 * *$ & $.40 * *$ & .71 & & \\
\hline $\begin{array}{l}\text { 9. Objective } \\
\text { severity }\end{array}$ & .13 & -.07 & .10 & .04 & $.26 *$ & $.38 * *$ & $.29 * *$ & $.40 * *$ & .77 & \\
\hline I0. SSII & $.29 * *$ & $-.64 * *$ & $.37 * *$ & .07 & $.28 * *$ & $.44 * *$ & $.31 * *$ & $.92 * *$ & .00 & - \\
\hline$M$ & 4.41 & 4.47 & 2.65 & 2.34 & 2.81 & 4.13 & 5.30 & 4.41 & 3.13 & 0.00 \\
\hline$S D$ & 1.03 & 1.71 & 1.57 & 1.30 & 1.69 & 1.88 & 1.49 & 1.47 & 1.20 & 0.99 \\
\hline
\end{tabular}

Note: $N=97$. NTBS = Need to Belong Scale; SFS = State Forgiveness Scale; ROL = repeat offense likelihood; SSII = subjective severity inflation index. Scale alphas appear on the diagonal.

$* p \leq .05 . * * p .001$.

Figure 1. Note that prior intimacy, $B=.37, t=5.49, p<.001$, was a statistically significant covariate, but offender apology, $B=.09, t=.33$, $n s$, was not (despite its zero-order association with the SFS).

Using the bootstrapping method described above (with 5,000 resamples), $95 \%$ bias-corrected and accelerated confidence intervals were computed to perform statistical tests of the indirect paths contained in the model (i.e., the paths from the NTBS to the SFS through anger, fear, sadness, repeat offense likelihood, intentionality, and offense severity) and the contrast of these indirect paths to compare the strengths of the mediators. Confidence intervals that do not contain zero denote statistically significant indirect paths and contrasts. A significant indirect effect also indicates a significant reduction in the direct relationship between the predictor and criterion variables of interest (as with the Sobel test).

The computed point estimates for the total indirect and specific indirect effects and confidence intervals are presented in Table 3. As can be seen in this table, the direct association between the NTBS and SFS, $B=-.33, t=-2.34$, $p=.02$, was significantly reduced to near zero $(B=.01)$ when the mediators were included. Among the possible mediators, however, only anger and offense severity were uniquely significant (i.e., the confidence intervals around their point estimates did not contain zero). None of the remaining mediators was significant above and beyond anger and severity.

Of the contrasts that were performed, only two were significant and are presented in Table 3: the contrasts between fear and offense severity and between sadness and offense severity. Because offense severity was the only significant mediator in these contrasts, these results do not deserve much attention. It is, however, important to note that the contrast between anger and offense severity was not significant, meaning that anger and offense severity mediated the

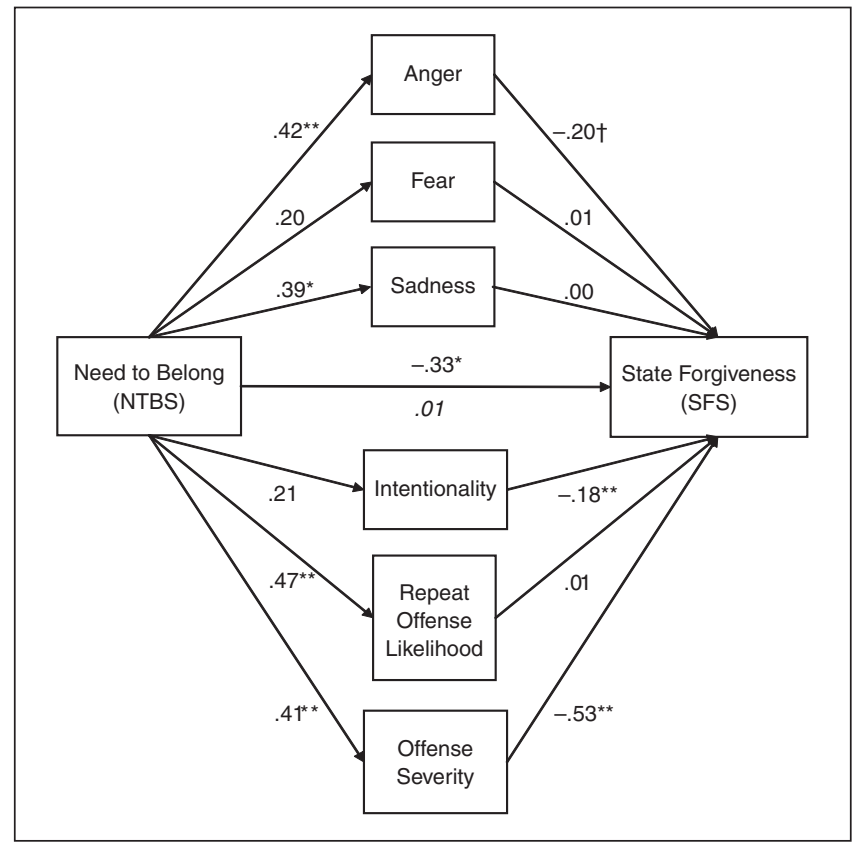

Figure I. Unstandardized path coefficients for the mediation of the NTBS-SFS relationship by anger, fear, sadness, intentionality, repeat offense likelihood, and offense severity (with covariates included)

Note: NTBS $=$ Need to Belong Scale; SFS $=$ State Forgiveness Scale. ${ }^{\dagger} p=.056 .{ }^{*} p \leq .02 .{ }^{*} p \leq .007$.

NTBS-SFS association to an equal extent as well as accounting for unique portions of this association.

The unique role of anger as a mediator of the association between need to belong and forgiveness suggests that people who have strong desires for acceptance and are concerned with being rejected withhold forgiveness from wrongdoers not because offenses make them sad or afraid but because 
Table 3. Mediation of the Association Between NTBS and SFS (Model With Offense Severity)

\begin{tabular}{|c|c|c|c|}
\hline & \multirow[b]{2}{*}{ Point estimate } & \multicolumn{2}{|c|}{$\begin{array}{l}95 \% \text { confidence } \\
\text { interval }\end{array}$} \\
\hline & & Lower & Upper \\
\hline $\begin{array}{l}\text { Total indirect effect of } \\
\text { mediator set }\end{array}$ & $-.348 \mid$ & -.5921 & -.0783 \\
\hline Anger & -.0853 & -.2739 & $-.000 \mathrm{I}$ \\
\hline Fear & .0042 & -.0443 & .0767 \\
\hline Sadness & -.0083 & -.0945 & .1205 \\
\hline Intentionality & -.0429 & -.1805 & .0264 \\
\hline $\begin{array}{l}\text { Repeat offense likeli- } \\
\text { hood }\end{array}$ & .0069 & -.1026 & .1184 \\
\hline Offense severity & -.2227 & -.5007 & -.0546 \\
\hline $\begin{array}{l}\text { Offense severity vs. } \\
\text { fear }\end{array}$ & .2269 & .0382 & .5213 \\
\hline $\begin{array}{l}\text { Offense severity vs. } \\
\text { sadness }\end{array}$ & .2144 & .0363 & .5491 \\
\hline
\end{tabular}

Note: NTBS = Need to Belong Scale; SFS = State Forgiveness Scale. Confidence intervals that do not include zero indicate statistical significance.

they make them angry, consistent with the notion that anger is often the emotional consequence of having progress toward an important goal disrupted (cf. Berkowitz, 1965). The primacy of anger in the model could also reflect the tendency among those high in the need to belong to perceive interpersonal offenses as especially unfair events, as has been found with individual differences in other contexts (e.g., Colquitt, Scott, Judge, \& Shaw, 2006; Hagedoorn, Buunk, \& Van de Vliert, 2002). The multiple mediator model also revealed that people high in the need to belong are less inclined to forgive wrongdoers because, for them, offenses are very severe experiences and not because they believe offenses will be repeated or that offenders meant to harm them. Moreover, both anger and offense severity ratings significantly and independently mediated the relationship between needing to belong and state forgiveness to the same degree, which indicates that the negative association between these variables is as much because of how offenses are responded to emotionally as how they are perceived.

Could it be that the inability of the other affective and cognitive variables to mediate the NTBS-SFS association results from our forcing these two sets of variables to compete against each other in our analyses? We tested this possibility by running separate multiple mediator models for each set of psychological variables - one for the affective measures and another for the cognitive ones. Conducting the analyses in this way did not change the role of any of the mediating variables - that is, anger was the only significant mediator in the affective set (point estimate $=-.1517,95 \%$ $\mathrm{CI}=-.3907$ to -.0362 ), and offense severity was the only significant mediator in the cognitive set (point estimate $=-.2411$,
$95 \% \mathrm{CI}=-.5150$ to -.0580 ). The pattern of mediation reported above, therefore, does not appear to be the result of including the affective and cognitive variables together in a single model.

Also, the correlational nature of our analyses leaves open the possibility that participants high in the need to belong might have selected more severe offenses from their life histories than participants who were relatively low in this need. To eliminate this as a possibility, two independent raters evaluated how hurtful, serious, offensive, and rejecting participants' offense experiences were, based on the descriptions participants provided. Ratings were averaged to create a composite objective severity score for each rater. The raters' composite severity judgments correlated highly, $r=.71$, $p<.001$, and were, therefore, combined into a single, objective severity score. Participants' subjective severity ratings (previously referred to as offense severity ratings) were regressed on objective severity ratings, and the residuals from this analysis served as an index of the extent to which participants exhibited "subjective severity inflation." We then reran the multiple mediator model described above but substituted the subjective severity inflation index (SSII) for participants' simple severity ratings in the original model. Prior intimacy emerged as a significant covariate in the model, $B=.33, t=4.77, p<.001$, but offender apology did not, $B=.16, t=.60, n s$. The point estimates and confidence intervals for this analysis are displayed in Table 4, and a diagram of the model we tested, including path weights, appears in Figure 2. Consistent with our original interpretation, the SSII significantly mediated the direct association between the NTBS and SFS; however, anger no longer appeared as a significant mediator, which we suspect would not be the case with a larger sample. As was true of the first model we tested, the direct connection between the NTBS and SFS was fully mediated in this new model, $B=-.01, t=-.11, n s$. Conclusions regarding the other mediators match those described above. From this follow-up analysis, it is possible to conclude that interpersonal offenses are meaningful affairs for people high in the need to belong - they construe these experiences as being more severe than objective observers do, and their tendency to see offenses in this biased fashion accounts, in large part, for their lack of forgiveness toward offenders.

\section{General Discussion}

Across three studies we examined the relationship between the need to belong and forgiveness and consistently found that the connection between these constructs supports Hypothesis 2 rather than Hypothesis 1-that is, a strong need to belong is associated with low rather than high levels of interpersonal forgiveness. Individuals who scored high on the NTBS in Study 1 reported that they were not especially forgiving people and said they valued forgiveness no more 
Table 4. Mediation of the Association Between NTBS and SFS (Model With Subjective-Objective Severity Discrepancy)

\begin{tabular}{lccr}
\hline & & \multicolumn{2}{c}{$\begin{array}{c}95 \% \text { confidence } \\
\text { interval }\end{array}$} \\
\cline { 3 - 4 } & $\begin{array}{c}\text { Point } \\
\text { estimate }\end{array}$ & Lower & Upper \\
\hline $\begin{array}{l}\text { Total indirect effect of } \\
\quad \text { mediator set }\end{array}$ & -.3275 & -.5354 & -.0774 \\
Anger & -.0702 & -.2542 & .0011 \\
Fear & .0035 & -.0477 & .0711 \\
Sadness & -.0224 & -.1179 & .0736 \\
Intentionality & -.0562 & -.1877 & .0404 \\
Repeat offense likelihood & -.0209 & -.1441 & .0688 \\
Subjective severity & -.1613 & -.3704 & -.0327 \\
$\quad$ inflation index (SSII) & & & \\
SSII vs. fear & .1648 & .0119 & .3748 \\
SSII vs. sadness & .1389 & .0075 & .4000 \\
\hline
\end{tabular}

Note: NTBS = Need to Belong Scale; SFS = State Forgiveness Scale. Confidence intervals that do not include zero indicate statistical significance.

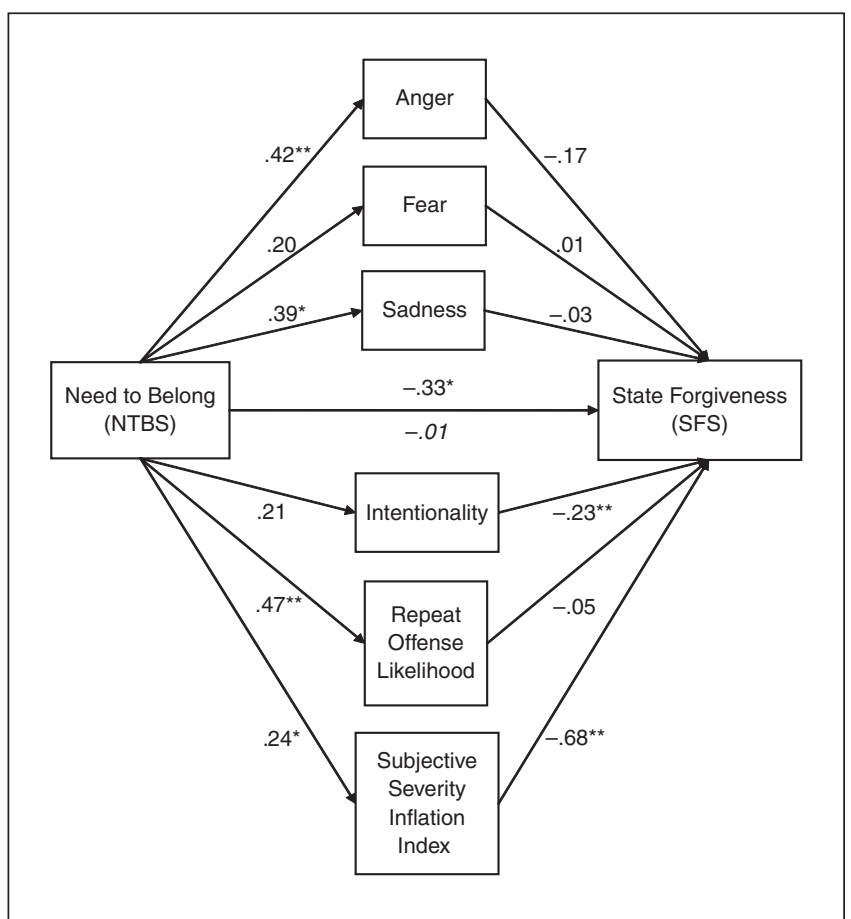

Figure 2. Unstandardized path coefficients for the mediation of the NTBS-SFS relationship by anger, fear, sadness, intentionality, repeat offense likelihood, and subjective severity inflation index (with covariates included)

Note: NTBS = Need to Belong Scale; SFS = State Forgiveness Scale. $* p \leq .02 .{ }^{* *} p \leq .005$

than people who scored low on the NTBS. Importantly, the association between the NTBS and forgiveness tendencies was unique and not attributable to individual differences in attachment security or rejection sensitivity. We conducted an experiment in Study 2 to establish a causal link between feelings of belongingness and forgiveness and found that individuals who wrote about an important close relationship in their lives predicted greater willingness to forgive a set of hypothetical offenses than did participants whose belongingness needs were left unaltered. The results of Study 2 also suggested that individuals in the former condition came to see themselves as more forgiving people in general than those in the latter condition, although their proforgiveness values remained unchanged. Thus, focusing attention on an important close relationship appears to be sufficient for momentarily satisfying belongingness needs and, in turn, bolstering people's willingness to forgive. We examined the association between the need to belong and state forgiveness for specific offenses in Study 3 and not only replicated the results of Study 1 with a state forgiveness measure but also successfully identified two important mediators of this relationship - namely, offense-related anger and perceptions of offense severity. Evidence also emerged to suggest that those high in the need to belong perceive offenses as being more severe than observers do, and the discrepancy between these judgments mediates the link between the need to belong and state forgiveness.

In sum, across three studies that utilized different methods (i.e., correlational and experimental) and tapped different aspects of forgiveness (dispositional forgiveness, forgiveness of hypothetical offenses, and state forgiveness for past offenses), we consistently found that the need to belong was negatively associated with forgiveness. Taken together, these studies break new ground by linking the need to belong with how people respond to interpersonal transgressions and contribute to the literature on how this fundamental motivation relates to important constructs in social psychology (e.g., Carvallo \& Pelham, 2006; DeWall et al., 2008; Mellor et al., 2008).

The cross-sectional nature of the data examined in Study 3 raises important questions about the causal ordering of the variables we included in our multiple mediator model (Spencer, Zanna, \& Fong, 2005). For instance, rather than the affective and cognitive variables occurring simultaneously in time, as our analyses imply, it is conceivable that the need to belong leads to negative perceptions of offenses that, in turn, lead to increased anger and lower levels of forgiveness. Future research that relies on longitudinal and experimental methodologies instead of cross-sectional data would be useful for clarifying the precise ordering of the mechanisms at work in the need to belong-forgiveness relationship. Similarly, it will be important for future research to consider other potential mediators than the cognitive and affective ones tested here. For instance, as suggested by an anonymous reviewer of this article, people who have a strong need to belong may withhold forgiveness to dissuade members of their social networks from engaging in offensive behaviors. Were this hypothesis supported empirically, 
it would point to the counterintuitive possibility that those who most desire social connectedness threaten others with social exclusion to keep their relational bonds intact.

We now come full circle to the paradoxical nature of the relationship between the need to belong and forgiveness that we alluded to in the introduction. Because stable, caring relationships are not always easy to come by, it is important for people to restore at least some of their damaged relationships to health following transgressions, and forgiveness may be one means of achieving this end. Interestingly, our results suggest that those we would expect to be the most apt to forgive wrongdoers - namely, those who chronically or momentarily experience heightened desires for belongingness - have difficulty doing so. Therefore, the need to belong might work against itself when it comes to preserving relational bonds that have been violated by a transgression. This leads us to wonder how often such people hold on to relationships with perpetrators they have not forgiven in a desperate effort to satisfy their social appetites. Because relationships in which old wounds are allowed to fester do not promote the true connectedness that humans desire, we believe that any attempt at reconciliation that is not accompanied by forgiveness may backfire by preserving relationships that ultimately cannot satisfy belongingness needs and by taking away from personal resources that could be used to build new relationships. This suggests that maintaining relationships in which personal injuries have not been forgiven could be as problematic as abandoning relationships the first time an injustice is suffered. In a world where caring relationships are a precious commodity, holding on to friends who have wronged us is important, but so, too, is forgiving them when we do.

\section{Declaration of Conflicting Interests}

The authors declared no potential conflicts of interests with respect to the authorship and/or publication of this article.

\section{Financial Disclosure/Funding}

The authors received no financial support for the research and/or authorship of this article.

\section{References}

Bartholomew, K., \& Horowitz, L. M. (1991). Attachment styles among young adults: A test of a four-category model. Journal of Personality and Social Psychology, 61, 226-244.

Baumeister, R. F., \& Leary, M. R. (1995). The need to belong: Desire for interpersonal attachments as a fundamental human motivation. Psychological Bulletin, 117, 497-529.

Baumeister, R. F., Stillwell, A. M., \& Wotman, S. R. (1990). Victim and perpetrator accounts of interpersonal conflict: Autobiographical narratives about anger. Journal of Personality and Social Psychology, 59, 994-1005.

Berkowitz, L. (1965). Some aspects of observed aggression. Journal of Personality and Social Psychology, 2, 359-369.
Berry, J. W., Worthington, E. L., Jr., Parrott, L., III, O’Connor, L. E., \& Wade, N. G. (2001). Dispositional forgivingness: Development and construct validity of the Transgression Narrative Test of Forgivingness (TNTF). Personality and Social Psychology Bulletin, 27, 1277-1290.

Bowlby, J. (1969). Attachment and loss: Vol. 1: Attachment. New York, NY: Basic Books.

Brown, R. P. (2003). Measuring individual differences in the tendency to forgive: Construct validity and links with depression. Personality and Social Psychology Bulletin, 29, 759-771.

Brown, R. P. (2004). Vengeance is mine: Narcissism, vengeance, and the tendency to forgive. Journal of Research in Personality, 38, 576-584.

Brown, R. P., Barnes, C. D., \& Judice-Campbell, N. (2007). Forgiveness and fundamentalism. Personality and Individual Differences, 43, 1437-1447.

Brown, R. P., \& Phillips, A. (2005). Letting bygones be bygones: Further evidence for the validity of the Tendency to Forgive Scale. Personality and Individual Differences, 38, 627-638.

Buckley, K. E., Winkel, R. E., \& Leary, M. R. (2004). Reactions to acceptance and rejection: Effects of level and sequence of relational evaluation. Journal of Experimental Social Psychology, 40, 14-28.

Burnette, J. L., Taylor, K. W., Worthington, E. L., Jr., \& Forsyth, D. R. (2007). Attachment and trait forgivingness: The mediating role of angry rumination. Personality and Individual Differences, 42, 1585-1596.

Bushman, B. J., Baumeister, R. F., \& Phillips, C. M. (2001). Do people aggress to improve their mood? Catharsis beliefs, affect regulation opportunity, and aggressive responding. Journal of Personality and Social Psychology, 81, 17-32.

Carvallo, M., \& Gabriel, S. (2006). No man is an island: The need to belong and dismissing avoidant attachment style. Personality and Social Psychology Bulletin, 32, 697-709.

Carvallo, M., \& Pelham, B. W. (2006). When fiends become friends: The need to belong and perceptions of personal and group discrimination. Journal of Personality and Social Psychology, 90, 94-108.

Colquitt, J. A., Scott, B. A., Judge, T. A., \& Shaw, J. C. (2006). Justice and personality: Using integrative theories to derive moderators of justice effects. Organizational Behavior and Human Decision Processes, 100, 110-127.

De Cremer, D., \& Leonardelli, G. J. (2003). Cooperation in social dilemmas and the need to belong: The moderating effect of group size. Group Dynamics: Theory, Research and Practice, 7, 168-174.

DeWall, C. N., Baumeister, R. F., \& Vohs, K. D. (2008). Satiated with belongingness? Effects of acceptance, rejection, and task framing on self-regulatory performance. Journal of Personality and Social Psychology, 95, 1367-1382.

DeWall, C. N., Twenge, J. M., Gitter, S. A., \& Baumeister, R. F. (2009). It's the thought that counts: The role of hostile cognition in shaping aggressive responses to social exclusion. Journal of Personality and Social Psychology, 96, 45-59. 
Diener, E., Larsen, R., \& Emmons, R. A. (1984). Person $\times$ situation interactions: Choice of situations and congruence responses models. Journal of Personality and Social Psychology, 47, 580-592.

Downey, G., \& Feldman, S. (1996). The implications of rejection sensitivity for intimate relationships. Journal of Personality and Social Psychology, 70, 1327-1343.

Emmons, R. A., \& Diener, E. (1986). An interactional approach to the study of personality and emotion. Journal of Personality, 54, 371-384.

Exline, J. J., \& Baumeister, R. F. (2000). Expressing forgiveness and repentance: Benefits and barriers. In M. E. McCullough, K. I. Pargament, \& C. E. Thoresen (Eds.), Forgiveness: Theory, research and practice (pp. 133-155). New York, NY: Guilford.

Gottman, J. M. (1993). A theory of marital dissolution and stability. Journal of Family Psychology, 7, 57-75.

Griffin, D. W., \& Bartholomew, K. (1994). Models of self and other: Fundamental dimensions underlying measures of adult attachment. Journal of Personality and Social Psychology, 67, 430-445.

Hagedoorn, M., Buunk, B. P., \& Van de Vliert, E. (2002). Do just world believers process unfair authoritative decisions differently? Applied Psychology: An International Review, 51, 126-145.

Joiner, T. E., Jr., Hollar, D., \& Van Orden, K. (2006). On Buckeyes, Gators, Super Bowl Sunday, and the Miracle on Ice: "Pulling together" is associated with lower suicide rates. Journal of Social and Clinical Psychology, 25, 179-195.

Kachadourian, L. K., Fincham, F., \& Davila, J. (2004). The tendency to forgive in dating and married couples: The role of attachment and relationship satisfaction. Personal Relationships, 11, 373-393.

Karremans, J. C., \& Van Lange, P. A. M. (2005). Does activating justice help or hurt in promoting forgiveness? Journal of Experimental Social Psychology, 41, 290-297.

Kelly, K. M. (1999). Measurement and manifestation of the need to belong (Unpublished doctoral dissertation). University of Tennessee, Knoxville.

Kirkpatrick, L. A., Waugh, C. E., Valencia, A., \& Webster, G. D. (2002). The functional domain specificity of self-esteem and the differential prediction of aggression. Journal of Personality and Social Psychology, 82, 756-767.

Lawler-Row, K. A., Younger, J. W., Piferi, R. L., \& Jones, W. H. (2006). The role of adult attachment style in forgiveness following an interpersonal offense. Journal of Counseling and Development, 84, 493-502.

Leary, M. R., Kelly, K. M., Cottrell, C. A., \& Schreindorfer, L. S. (2008). Individual differences in the need to belong: Mapping the nomological network. Unpublished manuscript, Duke University, Durham, NC.

Leary, M. R., Springer, C., Negel, L., Ansell, E., \& Evans, K. (1998). The causes, phenomenology, and consequences of hurt feelings. Journal of Personality and Social Psychology, 74, 1225-1237.
Leary, M. R., Tambor, E. S., Terdal, S. K., \& Downs, D. L. (1995). Self-esteem as an interpersonal monitor: The sociometer hypothesis. Journal of Personality and Social Psychology, 68, 518-530.

Leary, M. R., Twenge, J. M., \& Quinlivan, E. (2006). Interpersonal rejection as a determinant of anger and aggression. Personality and Social Psychology Review, 10, 111-132.

Maslow, A. H. (1968). Toward a psychology of being. New York, NY: Van Nostrand.

McCullough, M. E., Bellah, C. G., Kilpatrick, S. D., \& Johnson, J. L. (2001). Vengefulness: Relationships with forgiveness, rumination, well-being, and the Big Five. Personality and Social Psychology Bulletin, 27, 601-610.

McCullough, M. E., Pargament, K. I., \& Thoresen, C. E. (2000). The psychology of forgiveness: History, conceptual issues, and overview. In M. E. McCullough, K. I. Pargament, \& C. E. Thoresen (Eds.), Forgiveness: Theory, research and practice (pp. 1-14). New York, NY: Guilford.

McCullough, M. E., Rachal, K. C., Sandage, S. J., Worthington, E. L., Jr., Brown, S. W., \& Hight, T. L. (1998). Interpersonal forgiving in close relationships: II. Theoretical elaboration and measurement. Journal of Personality and Social Psychology, 75, 1586-1603.

McCullough, M. E., Worthington, E. L., Jr., \& Rachal, K. C. (1997). Interpersonal forgiving in close relationships. Journal of Personality and Social Psychology, 73, 321-336.

McKnight, P. E., McKnight, K. M., Sidani, S., \& Figueredo, A. J. (2007). Missing data. New York, NY: Guilford.

Mellor, D., Stokes, M., Firth, L., Hayashi, Y., \& Cummins, R. (2008). Need for belonging, relationship satisfaction, loneliness, and life satisfaction. Personality and Individual Differences, 45, 213-218.

Mickulincer, M., Shaver, P. R., Gillath, O., \& Nitzberg, R. A. (2005). Attachment, caregiving, and altruism: Boosting attachment security increases compassion and helping. Journal of Personality and Social Psychology, 89, 817-839.

Molden, D. C., Lucas, G. M., Gardner, W. L., Dean, K., \& Knowles, M. L. (2009). Motivations for prevention or promotion following social exclusion: Being rejected versus being ignored. Journal of Personality and Social Psychology, 96, 415-431.

Pickett, C. L., Gardner, W. L., \& Knowles, M. (2004). Getting a cue: The need to belong and enhanced sensitivity to social cues. Personality and Social Psychology Bulletin, 30, 1095-1107.

Preacher, K. J., \& Hayes, A. F. (2008). Asymptotic and resampling strategies for assessing and comparing indirect effects in multiple mediator models. Behavior Research Methods, 40, 879-891.

Richman, L. S., \& Leary, M. R. (2009). Reactions to discrimination, stigmatization, ostracism, and other forms of interpersonal rejection: A multilevel model. Psychological Review, 116, 365-383.

Rosenberg, M. (1965). Society and the adolescent self-image. Princeton, NJ: Princeton University Press. 
Schreindorfer, L., \& Leary, M. (1996, March). Seeking acceptance versus avoiding rejection: Differential effects on emotion and behavior. Paper presented at the meeting of the Southeastern Psychological Association, Norfolk, VA.

Spencer, S. J., Zanna, M. P., \& Fong, G. T. (2005). Establishing a causal chain: Why experiments are often more effective than mediational analyses in examining psychological processes. Journal of Personality and Social Psychology, 89, 845-851.

Tsang, J., McCullough, M. E., \& Hoyt, W. T. (2005). Psychometric and rationalization accounts for the religion-forgiveness discrepancy. Journal of Social Issues, 61, 785-805.

Twenge, J. M., Baumeister, R. F., Tice, D. M., \& Stucke, T. S. (2001). If you can't join them, beat them: Effects of social exclusion on aggressive behavior. Journal of Personality and Social Psychology, 81, 1058-1069.

Twenge, J. M., Zhang, L., Catanese, K. R., Dolan-Pascoe, B., Lyche, L. R., \& Baumeister, R. F. (2007). Replenishing connectedness: Reminders of social activity reduce aggression after social exclusion. British Journal of Social Psychology, 46, 205-224.

Warburton, W. A., Williams, K. D., \& Cairns, D. R. (2006). When ostracism leads to aggression: The moderating effects of control deprecation. Journal of Experimental Social Psychology, 42, 213-220.

Watson, D., Clark, L. A., \& Tellegen, A. (1988). Development and validation of brief measures of positive and negative affect: The PANAS scales. Journal of Personality and Social Psychology, 54, 1063-1070.

Watt, S. E., \& Badger, A. J. (2009). Effects of social belonging on homesickness: An application of the belongingness hypothesis. Personality and Social Psychology Bulletin, 35, 516-530.

Webb, M., Call, S., Chickering, S. A., Colburn, T. A., \& Heisler, D. (2006). Dispositional forgiveness and adult attachment styles. Journal of Social Psychology, 146, 509-512.

Williams, K. D. (1997). Social ostracism. In R. M. Kowalski (Ed.), Aversive interpersonal behaviors (pp. 133-170). New York, NY: Plenum.

Williams, K. D., Cheung, C. K. T., \& Choi, W. (2000). Cyberostracism: Effects of being ignored over the Internet. Journal of Personality and Social Psychology, 79, 748-762.

Williams, K. D., \& Sommer, K. L. (1997). Social ostracism by coworkers: Does rejection lead to loafing or compensation? Personality and Social Psychology Bulletin, 23, 693-706. 